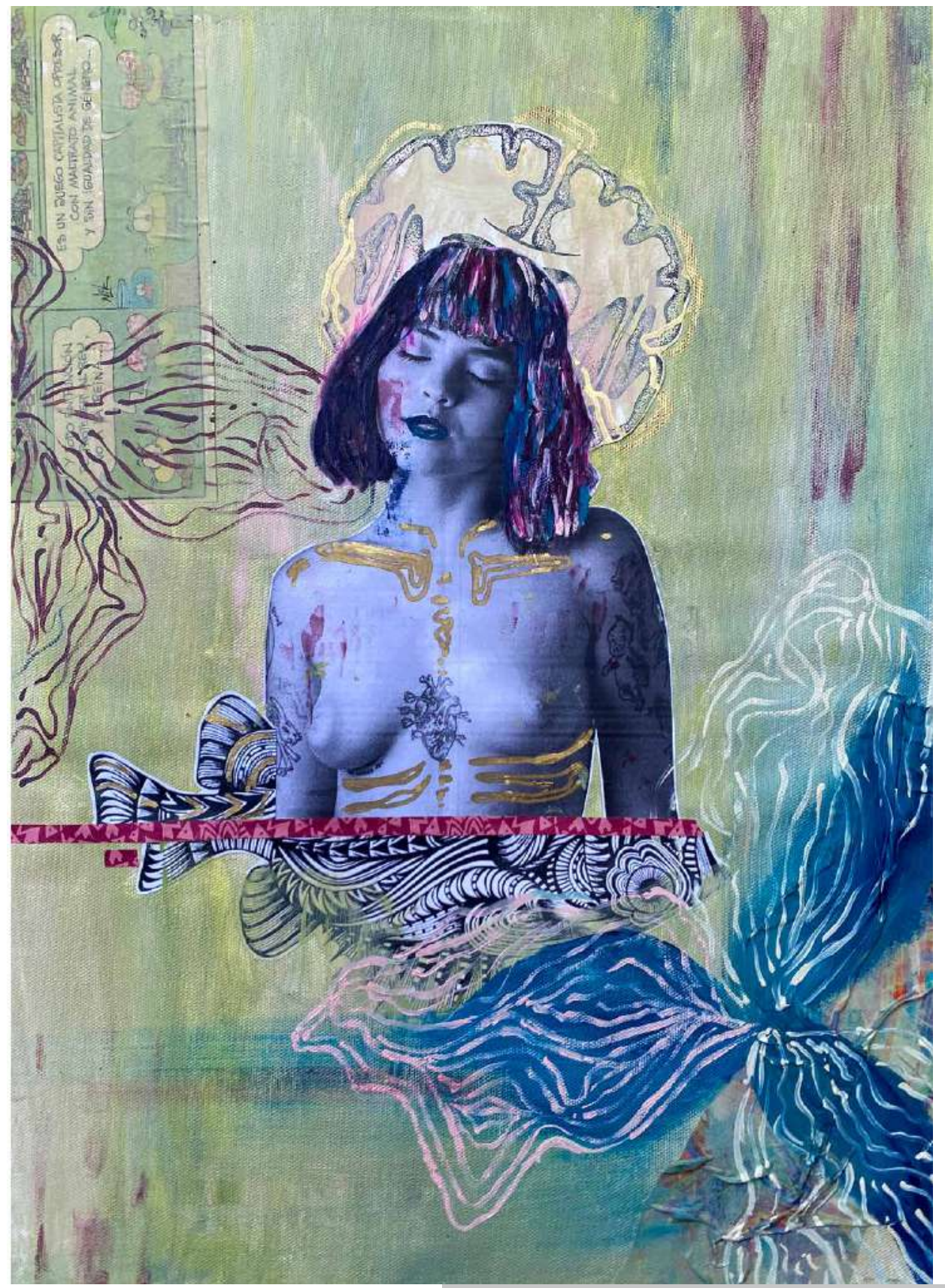

Artista invitada

Sofia Baraya Llaña

Paula Oliva

De la serie Ya no son chucherías

Técnica mixta

2020

Cortesía revista Ojo de Pez 


\section{Francisco Cortés Rodas. (2020). Del arte de la paz. Reflexiones filosóficas sobre justicia transicional. Bogotá, D. C.: Siglo del Hombre.}

\section{Resumen}

El libro Del arte de la paz. Reflexiones filosóficas sobre justicia, del conocido filósofo colombiano Francisco Cortés Rodas, es una valiosa contribución al debate sobre justicia transicional, teniendo siempre como punto de referencia el caso colombiano, pero situándolo en el contexto de las discusiones contemporáneas interdisciplinarias sobre justicia, memoria, perdón, derechos humanos y jurisprudencia internacional. La alusión en el título al «arte» de la paz es una referencia clara al sentido pragmático y prudencial de la propuesta de su autor, quien no se restringe a consideraciones meramente teóricas, sino que trata de aterrizarlas a contextos específicos que demandan soluciones concretas que no están exentas de controversia. Es mucho lo que se puede aprender de este libro.

\section{Palabras clave}

Paz; Justicia; Memoria; Perdón; Derecho Internacional; Derechos Humanos.

\section{En busca de una justicia prudencial en sociedades heridas}

La presentación del libro de Francisco Cortés se llevó a cabo en el marco de la Fiesta del Libro y la Cultura de Medellín el 3 de octubre de 2020, de manera virtual, con participantes que interveníamos desde España, Perú y Colombia. Estas conversaciones intercontinentales son hoy posibles y se han vuelto frecuentes gracias a las nuevas tecnologías, aunque, también hay que decirlo, se han incrementado debido a las secuelas de la terrible crisis sanitaria que ha generado la pandemia en todo el planeta y que nos tiene confinados y paralizados de muchas maneras. Podría decirse mucho sobre el significado que tiene esta crisis, en nuestra vida social o en nuestras relaciones personales, por ejemplo, que situaciones como esta son un caldo de cultivo para las teorías conspirativas de los más diversos tipos, para los falsos rumores, o también para la proliferación de los negacionismos y de las medidas populistas, como se ha podido apreciar largamente en la conducta de varios líderes mundiales o en manifestaciones callejeras delirantes en las calles de Lima, Bogotá o Berlín -y más recientemente en Washington-. 
Bajo el impacto de grandes conmociones sociales, ya sea por una epidemia, por enfrentamientos armados o por una guerra civil, incluso más si estos se prolongan en el tiempo, la opinión pública de nuestras sociedades no es muy proclive a buscar soluciones racionales y se deja arrastrar por una espiral de resentimiento y venganza que es muy difícil de detener. El juicio sobre lo más razonable se oculta tras posiciones maximalistas que impiden llegar a un acuerdo constructivo y se imponen emociones sociales primarias o la tendencia a culpabilizar a los otros; además, por supuesto, de la escasa disposición a reconocer las responsabilidades propias. Es muy difícil poner fin a una guerra, sobre todo a una guerra fratricida, y lo es más concertar la paz.

¿Cómo lograr la paz? Se trata, afirma Francisco Cortés en el título de su libro, de un «arte»: del arte de la paz. Confieso que el título me sorprendió cuando lo vi la primera vez y busqué por eso entre sus páginas una explicación del significado de esa palabra, arte, confiando ingenuamente en encontrar la fórmula que pudiera servir para resolver tantos conflictos que nos agobian. Por supuesto, esa explicación o esa fórmula no se encuentran en el libro, porque lo que se sugiere es que el arte de la paz es más bien un oficio o una disposición de carácter prudencial (p. 131), es decir, no una técnica, ni una definición teórica rígida, por más acertada que parezcan, sino una sabiduría práctica que se guíe, por supuesto, por principios éticos firmes, pero que sepa evaluar las circunstancias especiales de cada sociedad y tomar la decisión adecuada en el momento oportuno.

La paz, nos recuerda Francisco Cortés (pp. 156ss.), fue originariamente una diosa griega, Irene, y luego una diosa romana, Pax, hija de Justicia y de Júpiter —o Zeus—, es decir, heredera del derecho y la autoridad, pero fue entendida también como Concordia, es decir, como la convivencia armónica entre ciudadanos que acuerdan, concuerdan, dejar de lado las armas y vivir en conformidad con leyes reconocidas por ellos. Esa es, me parece, la inspiración que anima a la empresa del libro: contribuir al discernimiento de cuál es la paz más conveniente, más justa y duradera para nuestras sociedades, en especial, para la sociedad colombiana, más allá de las definiciones inflexibles que nos ofrecen los tratados de derecho y más allá, por cierto, de los movimientos negacionistas o vengativos de buena parte de la sociedad. 
Esa actitud prudencial es perceptible en la pluma de nuestro autor y en el itinerario que propone en su libro. Nos invita a revisar un conjunto de ensayos filosóficos divididos en siete capítulos, en los que explica por qué la teoría clásica de la justicia retributiva puede llegar a ser improcedente, o contraproducente, en sociedades que buscan resolver conflictos internos armados y por qué es más conveniente en tales casos recurrir a la justicia restaurativa en el marco de lo que se ha denominado en las últimas décadas «justicia transicional». Se arriesga también a ofrecer una reflexión más honda sobre el sentido del vínculo entre la memoria, el olvido y el perdón, así como una interpretación osada sobre el papel que desempeñan los distintos tipos de populismo en la construcción de nuestras democracias.

Lo que quería destacar, en refuerzo de mi comentario sobre la actitud prudencial del autor, es que los ensayos son como el testimonio de un mensaje reiterado, de una causa por la que él viene luchando desde hace varios años en diversos foros y en varios países. En la misma publicación se consigna la fuente de la que proceden los textos de los ensayos: un congreso en Ciudad de México, organizado por colegas de filosofía política; un libro de homenaje al presidente de la Comisión de la Verdad de Perú sobre justicia y memoria; un coloquio internacional interdisciplinario sobre los rostros del perdón; un debate en Buenos Aires sobre casos comparativos de justicia transicional; y varios eventos más — coloquios, mesas redondas, conferencias - organizados por el propio Francisco Cortés en Colombia, a los que invitó a muchos especialistas internacionales. En el libro ha quedado registrado como hilo conductor, en sintonía con su tesis central, el empeño y el compromiso personales por hacer comprensible, desde un punto de vista filosófico, la necesidad de buscar un arte prudencial de construcción de la paz.

Ahora bien, el tema central que atraviesa toda la empresa, y sobre el que se vuelve reiteradamente, es, claro está, el Acuerdo de Paz entre el Gobierno de Colombia y las guerrillas de las FARC-EP. Todo gira en torno a las razones de su legitimidad y al desconcertante y encendido disenso que se vive en esa sociedad, dividida entre los que están a favor y los que están en contra, y gobernada precisamente por quienes están en contra del Acuerdo. Hay, pues, un motivo político, una toma de posición deliberada en un debate en curso, que le da una actualidad a los argumentos esgrimidos 
en los ensayos del libro. También esto es un ingrediente de la idea de un arte prudencial.

Que la sociedad colombiana esté así de dividida —como lo está, por cierto, la sociedad peruana con respecto al procesamiento de su memoria nacional- es un asunto que merece más de una explicación, al menos, una explicación teórica y otra práctica. La explicación teórica se puede resumir en una reflexión de Priscilla Hayner (2001), en la que se refería a un dilema constitutivo e insoluble de cualquier comisión de la verdad, o de cualquier acuerdo o relato sobre la memoria de una sociedad luego de un conflicto armado. Sostiene ella que estas comisiones, o bien se crean en medio de un conflicto - $y$ entonces deben ceder a las presiones de ambos bandos, con lo cual no llegan a la verdad, ni a la justicia en su sentido más estricto, sino a un compromiso naturalmente deficiente desde un punto de vista ético o jurídico-, o bien se crean luego de un conflicto - y entonces llevan el sello o el sesgo de la verdad que ha elaborado la parte vencedora, la «historia oficial»—, que se aleja igualmente de la justicia en su sentido estricto. El dilema es muy serio y de él se hallan pruebas en prácticamente todos los acuerdos de paz o comisiones de la verdad de las últimas décadas. La explicación práctica, por su parte, habría que buscarla —en Colombia o en Perú - en la tentación de buena parte de nuestras sociedades, sobre todo de la clase política o empresarial, de practicar alguna forma de negacionismo, es decir, de no extraer lecciones de lo vivido, de no asumir responsabilidades por lo hecho o por lo omitido, de cerrar los ojos a las causas más profundas de la violencia, de pretender seguir viviendo como si nada hubiera pasado.

Quiero mencionar a continuación, muy brevemente, tres grandes problemas que son tratados con amplitud en el libro y haré al respecto solamente una reflexión general, motivado por la invitación a pensar que nos hace el autor sobre una materia tan polémica. El primero de ellos es el de la memoria y su relación con el olvido. Concuerdo con el autor en la necesidad de preservar, de narrar, una memoria ética de lo vivido y comparto su resistencia contra las políticas del olvido, las sofisticadas - como la de David Rieff (pp. 134ss.) — y las negacionistas — como las de ciertos partidos políticos-. Las víctimas tienen un derecho a saber y la sociedad tiene el deber de reconstruir su conciencia nacional. Me pregunto solamente si la tesis de Tzvetan Todorov, aquella que privilegia una memoria «ejemplar» 
por sobre una memoria «literal» no sería la más apropiada para casos tan duros como este (p. 138). Me parece entender que Francisco Cortés se encamina también en esta dirección.

El segundo problema es la cuestión del perdón, el cual ocupa también un espacio significativo en el libro. Confieso que tengo en este caso ciertas reservas ante el empleo que se hace de esta noción en el ámbito político y en el jurídico en el marco de la justicia transicional. El asunto, naturalmente, no depende ya ahora de opiniones personales, porque el término ha pasado a formar parte del lenguaje jurídico internacional. Pero mi impresión es que, de esta manera, se corre el riesgo de perder de vista una asimetría esencial en el verbo perdonar, que es la que diferencia al acto de pedir perdón del acto de otorgar el perdón. Se puede, sí, exigir, incluso en términos políticos, que alguien pida perdón, pero no se puede nunca exigir a nadie que lo otorgue, menos pensar que el Estado se reserve esa prerrogativa. Entiendo que pueda decidirse en ciertos casos reducir las penas por razones hasta estratégicas, pero no creo que sea acertado llamar a eso «perdón».

El tercer y último problema es el del populismo. No entiendo, a decir verdad, por qué debe tratarse este problema en el marco de la reflexión sobre el Acuerdo de Paz, e incluso me temo que puede ser contraproducente para la posición que defiende el autor. Se afirma, ciertamente con razón, que habría una diferencia clara entre el populismo de derecha y el de izquierda, porque el primero promueve la discriminación y el racismo, mientras que el segundo promueve una protesta justificada del pueblo contra la opresión de que es víctima; pero se añade, ya no sé si con razón, que el populismo de izquierda sería en algún sentido positivo y favorable para el desarrollo de nuestras democracias. Con franqueza, no lo creo, y no lo creo por los motivos que el propio Francisco Cortés señala como consustanciales al populismo, a saber: la necesidad de un líder carismático y la supresión de las mediaciones institucionales que son indispensables en toda democracia. $\mathrm{Si}$ estamos imaginando una sociedad civil reflexiva, capaz de adherirse con buenas razones a un acuerdo prudencial sobre la justicia transicional, entonces imaginémonos también un movimiento político democráticamente más articulado y horizontal.

Se debe saludar y agradecer la palabra comprometida de un filósofo que adopta una posición personal y ofrece elementos de juicio para 
contribuir a la concordia de su sociedad en medio de un proceso en curso. Hacen falta para ello valentía y perspicacia, además de la conciencia de que algunos juicios pueden tener validez solo pasajera. Francisco Cortés nos induce a pensar y contribuye de una manera muy fecunda a ejercer el arte de la paz.

Miguel Giusti (Perú)*

\section{Referencias bibliográficas}

1. Hayner, Priscilla B. (2001). Unspeakable Truths. Transitional Justice and the Challenge of Truth Commissions. Nueva York: Routledge.

* Doctor en Filosofía. Profesor principal del Departamento de Humanidades, Pontificia Universidad Católica del Perú. Correo electrónico: mgiusti@pucp.edu.pe - Orcid: 0000-0002-9837-9981 - Google Scholar: https://scholar.google.com/citations?user=rKPCjxYAAAAJ\&hl=es 